\title{
Correlation of the Korean Version of Falls Efficacy Scale-International With Quantitative Balance and Gait Parameters Through Exercise Program in Elderly Men
}

\author{
Bo Ram Ahn, MD, Hyo Jung Kang, MD, Eun Jung Choi, MD, \\ Soo Woong Jang, MD, Hee Sup Chung, MD, Kyung Soo Jeon, MD
}

Department of Physical Medicine and Rehabilitation, Veterans Health Service Medical Center, Seoul, Korea

\begin{abstract}
Objective To determine correlation of the Korean version of Falls Efficacy Scale-International (KFES-I) with other gait and balance parameters through exercise program in older men.

Methods Between July 2015 and April 2018, 50 men of 103 participants in an exercise program for preventing falls who aged over 60 years, completed the evaluation before and after the program, had fear of falling (FOF), and could walk independently as an outpatient were enrolled retrospectively. The program comprised lower extremities and core muscle strengthening exercises following stretching exercises twice a week for 8 weeks. FOF using the KFES-I, Berg Balance Scale (BBS), Modified Barthel Index (MBI), stair up and gait categories in MBI (MBI-gait), and Timed Up and Go test (TUG) were evaluated. Quantitative gait and balance parameters were measured by gait analysis, posturography, and isokinetic dynamometer. They were compared before and after the program. Moreover, correlations of KFES-I with other parameters were examined.

Results Fifty participants were enrolled. After the program, significant improvements were noted in right stride length ( $\mathrm{p}=0.013)$ in gait analysis, MBI $(\mathrm{p}=0.012)$, BBS $(\mathrm{p}<0.000)$, TUG test $(\mathrm{p}<0.000)$, and KFES-I $(\mathrm{p}<0.000)$ scores. KFES-I was significantly correlated with MBI ( $r=-0.35, \mathrm{p}=0.013)$, and MBI-gait $(\mathrm{r}=-0.341, \mathrm{p}=0.015)$.

Conclusion Risk of falls could be significantly improved through exercise. KFES-I had significant correlations with MBI-gait parameters. Participants showed increases in gait and balancing ability on quantitative measurements through exercises. Therefore, regular stretching, strengthening, and balancing exercises may help prevent falls in older people.
\end{abstract}

Keywords Elderly, Exercise, Koreans, Falls, Fear

Received August 23, 2018; Accepted October 8, 2018

Corresponding author: Hyo Jung Kang

Department of Physical Medicine and Rehabilitation, Veterans Health Service Medical Center, 53 Jinhwangdo-ro 61-gil, Gangdong-gu, Seoul 05368, Korea. Tel: +82-2-2225-1399, Fax: +82-2-2225-1569, E-mail: khojing@hanmail.net

ORCID: Bo Ram Ahn (http://orcid.org/0000-0003-4236-6775); Hyo Jung Kang (http://orcid.org/0000-0001-7429-1101); Eun Jung Choi (http://orcid. org/0000-0001-7894-1730); Soo Woong Jang (http://orcid.org/0000-0002-9955-6265); Hee Sup Chung (http://orcid.org/0000-0002-1879-502X); Kyung Soo Jeon (http://orcid.org/0000-0002-2282-2780).

(c) This is an open-access article distributed under the terms of the Creative Commons Attribution Non-Commercial License (http://creativecommons.org/ licenses/by-nc/4.0) which permits unrestricted noncommercial use, distribution, and reproduction in any medium, provided the original work is properly cited. Copyright @ 2019 by Korean Academy of Rehabilitation Medicine 


\section{INTRODUCTION}

Falls frequently lead to serious morbidity and increase mortality in older people who are especially susceptible to morbidity and mortality [1]. They can cause bruises, lacerations, fractures, or traumatic brain injury [2]. Recently, with societal aging, falling has become an important issue as it can increase the risk of death, worsen quality of life, and lead to long-term hospitalization in older people $[2,3]$. In South Korea, $42 \%$ of elderly people have experienced falling and $38 \%$ of them have high medical expenses [4].

Fear of falling (FOF) is a consistent concern of falling. It prevents the elderly from walking on roads or limits their daily performances. This has many adverse consequences, including decreased functional ability and quality of life [5,6], muscle weakness [7], and even falls [8]. Moreover, FOF is an important psychological factor that restricts social activities and increases psychological anxiety [9]. It influences balance control and increases the risk of falls [5]. The elderly who experience fall would also develop FOF consequently and avoid daily and social activities which in turn can increase the risk of falls. Fall and FOF show independently positive correlation $[5,8]$. Thus, FOF should be evaluated to prevent falls.

In 1990, the Fall Efficacy Scale by Tinetti et al. [10] was developed for evaluating FOF. However, it was not intended for the elderly who could afford high level of social activity. Hence, Activities-specific Balance Confidence scale was later developed to focus on the elderly with good performance level [11]. Finally, Falls Efficacy Scale-International (FES-I) was created. It integrates the Fall Efficacy Scale and the Activities-specific Balance Confidence scale [12]. It can be used for easy and difficult physical performance evaluation and measurement of social activity [12,13]. In South Korea, reliability and validity of the Korean version of Falls Efficacy ScaleInternational (KFES-I) have been proven [14]. However, few studies have evaluated FOF using the KFES-I tool in Korea.

Our hospital investigated the guideline for fall prevention in Korea and designed our own exercise program [15]. It composed of stretching, strengthening, and balancing exercise of the lower extremities and core muscles twice a week for 30 minutes during 8 weeks. We attempted to primarily evaluate whether the exercise pro- gram could decrease FOF using KFES-I in elderly people after an 8-week exercise. In addition, we applied more quantitative gait and balance parameters of gait analysis, isokinetic dynamometer, and posturography for objective results than parameters used in other studies [16-18]. Accordingly, this study was conducted to evaluate correlations of KFES-I with quantitative gait and balance variables, including spatiotemporal variables by gait analysis, stride length $(\mathrm{cm})$, walking speed $(\mathrm{cm} / \mathrm{s})$, cadence (steps/ min), proportion of stance phase, single limb support, initial double stance (IDS), terminal double stance (TDS) in gait cycle (\%), knee maximal extensor strength using an isokinetic dynamometer at an angular velocity of 120 $\mathrm{rad} / \mathrm{s}$ and $210 \mathrm{rad} / \mathrm{s}$, stability index (SI), and Weight Distribution Index (WDI) by posturography. Furthermore, we aimed to compare results based on the experience of fall.

\section{MATERIALS AND METHODS}

\section{Study design}

This study retrospectively reviewed medical records of outpatient subjects who participated in the exercise program for preventing falls between July 2015 and April 2018.

Age, sex, height, weight, fall experience, and fracture history at falls of all participants were reviewed. Their medication prescriptions were reviewed and categorized into none, cardiovascular, diuretics, antipsychotic, and hypnotic medications for sleeplessness, pain medication such as NSAIDs or opioid, and muscle relaxant. Then, total numbers of the above medications per each patient were counted. Concomitant diseases associated with falls were also reviewed for all participants. They were categorized into cerebrovascular accident including lacunar infarction, cervical/lumbar vertebral disease, degenerative disease at hip/knee/ankle joints, and visual/ hearing defects (Table 1). All participants were evaluated for bone mineral density (BMD) and Mini-Mental State Examination (MMSE) before the exercise. They were also evaluated for range of motion (ROM) on both hip, knee, and ankle joints, manual muscle test (MMT) in both lower extremities, isokinetic maximal strength using isokinetic dynamometer, gait analysis parameters (spatiotemporal parameters, such as walking speed, stride length, cadence, single limb support, and double limb 
Table 1. Baseline characteristics of participants $(n=50)$

\begin{tabular}{|cc|}
\hline \multicolumn{1}{c}{ Characteristic } & Value \\
\hline Sex & \\
\hline Male & 50 \\
\hline Female & $71.80 \pm 4.07$ \\
\hline Age $(\mathrm{yr})$ & $167.40 \pm 4.71$ \\
\hline Height $(\mathrm{cm})$ & $33(66)$ \\
\hline Fall experience & $1.45 \pm 1.3$ \\
\hline Number of fall & $11(33)$ \\
\hline Fracture history (n=33) & $23.54 \pm 2.39$ \\
\hline BMI (kg/m $\left.{ }^{2}\right)$ & \\
\hline Bone mineral density & $-0.50 \pm 1.70$ \\
\hline At spine & $-0.60 \pm 0.92$ \\
\hline At right femur neck & $-0.68 \pm 0.95$ \\
\hline At left femur neck & $26.67 \pm 3.47$ \\
\hline MMSE & $2.80 \pm 1.07$ \\
\hline Total number of medication & \\
\hline Disease category & 17 \\
\hline CVA including lacunar infarction & 23 \\
\hline Cervical/lumbar vertebral disease & 10 \\
\hline Degenerative disease at & \\
\hline the hip/knee/ankle joints & 0 \\
\hline Visual/hearing defect & \\
\hline
\end{tabular}

Values are presented as mean \pm standard deviation or number (\%).

BMI, body mass index; CVA, cerebrovascular accident; MMSE, Mini-Mental State Examination.

support proportion in gait cycle), balance ability using Berg Balance Scale (BBS) and posturography, FOF using the KFES-I, functional ability using the Modified Bathel Index (MBI), summation scores of stair up and gait categories in MBI (MBI-gait), and Timed Up and Go test (TUG) before and after the exercise program. A group of 7 to 10 participants joined the exercise program with 30 minutes duration twice a week for 8 weeks. The program consisted of stretching, strengthening, and balancing exercises. Outcome measurements were obtained before and after 16 sessions of the exercise program.

\section{Subjects}

We included participants who aged over 60 years, experienced FOF, engaged over 10 sessions of the total 16 sessions, and could visit the hospital independently as an outpatient regularly. We excluded participants with severe cognitive impairment who were unable to follow 3-step command in MMSE or with visual problem who were unable to follow the exercise program, who needed assistance or help for gait or activity of daily living, who had limited ROM on limb joints that prevented participants from following the exercise with sitting, standing, bridging, and quadruped positions, who experienced severe pain during exercises for back and lower limbs, who had stroke history in the last 1 year, and had history of limb surgery. Of 103 participants in the exercise program for preventing falls between July 2015 and April 2018, 50 men were reviewed and enrolled retrospectively upon satisfying the inclusion criteria. Fifty-three participants were excluded due to low number of attendance $(n=25)$, patients' refusal $(n=10)$, measurement refusal after the exercise program $(n=7)$, other disease occurrence $(n=8)$, cognitive impairment $(n=1)$, or limb amputation $(n=2)$. The study's protocol was approved by the Institutional Review Board of Veterans Health Service Medical Center (No. BOHUN 2018-08-016).

\section{Assessments for outcome parameters \\ KFES-I}

To evaluate participant's FOF, we used the KFES-I, a questionnaire composed of 16 items of gait, activities of daily living, and social activities [14]. Each item was graded from 1 (not at all concerned) to 4 (very concerned which means having cognitive disquiet about the possibility of falling). Total scores were summated, with higher score indicating higher anxiety for falls.

\section{Spatiotemporal parameters using three-dimensional} motion analysis for gait analysis

The three-dimensional motion analysis (3DMA) is a system that quantitatively measures spatiotemporal, kinematic, and kinetic gait parameters. Gait analysis was conducted using an 8 infrared, $60-\mathrm{Hz}$ camera motion analysis system (Motion Analysis Corp., Santa Rosa, CA, USA) and three force plates (sampling rate 1,200 Hz; Kistler Instrument Corp., Amherst, NY, USA). Reflective markers were placed on predefined anatomical landmarks of the pelvis, thigh, knee, shank, and foot [19]. Simultaneous recordings of spatiotemporal and lower extremity kinematics and kinetics (foot-floor contact patterns) were obtained as patients walked barefoot for $6 \mathrm{~m}$ at their self-selected walking speed. This study used the following spatiotemporal variables: stride length $(\mathrm{cm})$, 
walking speed $(\mathrm{cm} / \mathrm{s})$, cadence (steps/min), proportion of the stance phase, single limb support, initial double limb support, and terminal double limb support in the gait cycle (\%).

\section{Knee extensor maximal strength}

Participants were positioned on an isokinetic dynamometer (CYBEX; Computer Sports Medicine Inc., Stoughton, MA, USA) to assess bilateral lower extremity maximal strength. They were seated with the hip joint at $85^{\circ}$ of flexion based on the manufacturer's recommendations and fixed to constant measurement for maximal strength. In addition, we evaluated participant's knee maximal extensor strength using an isokinetic dynamometer at angular velocity of $120 \mathrm{rad} / \mathrm{s}$ and $210 \mathrm{rad} / \mathrm{s}$.

\section{Balance parameters}

Test for balancing parameters (as SI and WDI) were performed using tetra-ataxiometric posturography (Tetrax; Sunlight Medical Ltd., Ramat Gan, Israel). The SI score represents the ability to maintain good dynamic balance measured by the frequency of weight change in four force plates, with a lower score indicating more stable balanced status. In addition, WDI showed distribution of weight on the four force plates with normal distribution of $25 \%$ for each plate. Higher WDI indicated changes in weight distribution, meaning an unstable balanced state.

BBS evaluates balance in three positions (sitting, standing, and changing position) composed of 14 categories. Each category was scored into 0 to 4 (highest score, 56 points), with higher score indicating better balance.

\section{Other variables}

In the TUG test, one examiner observed the subject as he rose from a standard arm chair, walked a fixed 3-m distance across the room, turned around, walked back to the chair, and sat down. The rated time from rising to siting was the result of the TUG test. BMD, ROM, and MMT on both hips, knees, and ankle joints and muscles, MMSE, and MBI including MBI-gait were measured before and after the exercise program except for BMD and MMSE.

\section{Exercise program for fall prevention}

The exercise program consisted of stretching, strengthening, and balancing exercises of the lower extremities and core muscles for 30 minutes twice a week for 8 weeks [15]. This program was performed with participants in groups of 7 to 10 . Two physical therapists educated participants by showing them the specific position for each exercise. The same therapists have been constantly involved since 2015. Before and after every exercise, a stretching program for 5 minutes was added to prevent trauma. The program was composed of stretching, strengthening, and balance exercises. It was performed every week as described below. Its intensity was determined by compliance and performance status of the individual.

(1) The first week (ROM exercises and ankle stabilizing exercises using Thera Bands)

- Resistive ROM exercise on hip, knee, and ankle joints with sitting position.

(2) The second week (Lower extremity strengthening exercise on the ground)

- Ankle cuff weight, strengthening exercise with Thera Bands with sitting position.

(3) The third week (Lower extremity strengthening exercise in standing position)

- Squat exercise with back support using a gym ball.

- Strengthening exercises on knee and hip extensor in standing position.

(4) The fourth week (Lumbar spine stabilizing exercise on the ground)

- Bridge exercise, quadruped opposite arm with keeping back straight.

(5) The fifth week (Dynamic lumbar spine stabilizing exercise using a gym ball)

- Control trunk left to right with arm abduction seated on gym ball.

(6) The sixth week (Advanced lumbar spine stabilizing exercise)

- Alternatively quadruped opposite arm and leg while keeping back straight.

- Prone position with alternatively opposite arm and leg elevation.

(7) The seventh week (Balance training)

- Sit to stand exercise, tandem standing, tandem gaiting, change of direction.

(8) The eighth week (Advanced balance training using a balancing board) 


\section{Statistical analyses}

The Statistical Package for Social Sciences software version 18.0 (SPSS Inc., Chicago, IL, USA) was used for all statistical analyses. The Kolmogorov-Smirnov test was used to investigate distribution of data. All KFES-I, gait analysis parameters, posturography data except SI, and isokinetic parameters were normally distributed while ROM, MMT, MBI, BBS, TUG, SI parameters in posturography, or TDS in gait analysis was not normally distributed. Paired t-test was used for comparison of normally distributed variables while Wilcoxon signed-rank test was used for not normally distributed variables. To compare the group with fall experience and the group without fall experience, delta values were calculated between preand post-exercise values. Comparisons between groups were done by independent t-test for normally distributed variables and by Mann-Whitney U test for not normally distributed variables. Pearson test for normal distribution data and Spearman correlation test for not normally distributed data were used to evaluate correlations of KFES-I with other parameters. A p-value of less than 0.05 was considered statistically significant.

\section{RESULTS}

All participants completed the evaluation before and after the exercise program. Baseline characteristics of participants are summarized in Table 1.

\section{Outcome differences before and after the exercise program}

Parameters before and after the fall prevention program are presented in Table 2 .

After the exercise program, significant improvements in the right stride length $(\mathrm{p}=0.01)$ of gait analysis, knee extensor maximal strength on both sides with angular velocities of $120 \mathrm{rad} / \mathrm{s}$ and $210 \mathrm{rad} / \mathrm{s}(\mathrm{p}<0.00$ and $\mathrm{p}<0.00)$, MBI ( $p=0.012)$, MBI-gait ( $p=0.036)$, BBS $(p<0.00)$, TUG test $(\mathrm{p}<0.000)$, and KFES-I $(\mathrm{p}<0.000)$ were noted. However, ROM and MMT including cadence, walking speed, the proportion of IDS and TDS in gait cycle by gait analysis, and WDI and SI in posturography showed no significant changes.

\section{Correlations of KFES-I with other quantitative gait parameters}

KFES-I was significantly correlated with MBI $(r=-0.350$, $\mathrm{p}=0.013)$ and MBI-gait $(\mathrm{r}=-0.341, \mathrm{p}=0.015)$.

\section{Comparison of parameters based on fall experience}

Of 50 participants, 33 had fall experiences and 17 had no fall experience. In the comparison of the effect of exercise based on fall experience, KFES-I, MBI, and MBIgait parameters were similar between the two groups ( $\mathrm{p}=0.24, \mathrm{p}=0.21$, and $\mathrm{p}=0.37$, respectively). However, there were significant differences in KFES-I before (faller $39.18 \pm 12.47$, non-faller $30.82 \pm 10.77$; $=0.023$ ) and after the exercise program (faller $33.48 \pm 12.44$, non-faller 25.12 $\pm 8.62 ; \mathrm{p}=0.008)$.

\section{DISCUSSION}

In this retrospective study, we attempted to primarily evaluate effects of exercise program in decreasing FOF using KFES-I in elderly people after an 8-week exercise. In addition, we applied more quantitative gait and balance parameters of gait analysis, isokinetic dynamometer, and posturography for objective results compared to previous studies. Therefore, we aimed to determine correlations of the KFES-I with other gait and balance parameters through exercise program in older men. We observed an increase of functional and balancing ability in participants through exercises for preventing falls. KFES-I scores were improved, suggesting a decrease in FOF which was significantly correlated with MBI gait parameters. Thus, regular stretching, strengthening, and balancing exercises may help prevent falls in older people.

FOF is known to be a strong risk factor of balance disorders and falls that increase with age [5-9,20]. Although FOF makes an individual become protective of cautious situations, it can also result in excessive avoidance, reduced activities, and increased risks of falls. As a result, fall and FOF show close relationship, making a vicious cycle by increasing each other and finally aggravating physical, social, and psychological status of the elderly [5-9]. FES-I was developed to measure fall efficacy of FOF with regard to physical, social, and psychological concerns $[12,13]$. Several studies have evaluated fall efficacy using FES in community-dwelling elders and showed a 
Table 2. Comparison of parameters between before and after the exercise program

\begin{tabular}{|c|c|c|c|c|c|c|}
\hline \multirow{2}{*}{ Parameter } & \multicolumn{2}{|c|}{ Before } & \multicolumn{2}{|c|}{ After } & \multicolumn{2}{|c|}{ p-value } \\
\hline & Right & Left & Right & Left & Right & Left \\
\hline \multicolumn{7}{|l|}{ Gait analysis } \\
\hline Cadence (steps/min) & $96.90 \pm 23.04$ & $96.71 \pm 22.80$ & $95.93 \pm 21.17$ & $96.51 \pm 21.34$ & 0.90 & 0.79 \\
\hline Gait velocity $(\mathrm{cm} / \mathrm{s})$ & $69.56 \pm 27.87$ & $70.01 \pm 28.51$ & $96.51 \pm 21.34$ & $72.21 \pm 30.90$ & 0.12 & 0.06 \\
\hline Stride length $(\mathrm{cm})$ & $83.82 \pm 22.25$ & $84.22 \pm 22.37$ & $87.17 \pm 26.07$ & $84.87 \pm 29.35$ & $0.01^{*}$ & 0.59 \\
\hline Stance phase (\%) & $66.81 \pm 5.01$ & $64.33 \pm 7.06$ & $65.89 \pm 5.21$ & $65.06 \pm 5.22$ & $0.09^{*}$ & 0.57 \\
\hline Single support (\%) & $34.93 \pm 5.81$ & $33.19 \pm 5.00$ & $35.22 \pm 5.25$ & $34.13 \pm 5.23$ & 0.68 & $0.09^{*}$ \\
\hline IDS & $16.08 \pm 5.07$ & $15.63 \pm 5.28$ & $15.39 \pm .30$ & $15.42 \pm 5.18$ & 0.21 & 0.62 \\
\hline TDS & $15.79 \pm 5.08$ & $16.25 \pm 5.02$ & $17.25 \pm 14.74$ & $15.25 \pm 4.05$ & 0.56 & 0.12 \\
\hline \multicolumn{7}{|c|}{ Isokinetic dynamometer ${ }^{\mathrm{a})}$} \\
\hline $120 \mathrm{rad} / \mathrm{s}$ & $26.59 \pm 19.08$ & $29.98 \pm 21.09$ & $38.12 \pm 24.82$ & $42.67 \pm 26.99$ & $0.00^{*}$ & $0.00^{*}$ \\
\hline $210 \mathrm{rad} / \mathrm{s}$ & $19.84 \pm 13.59$ & $22.92 \pm 14.53$ & $29.96 \pm 19.52$ & $32.22 \pm 20.09$ & $0.00^{*}$ & $0.00^{*}$ \\
\hline \multicolumn{7}{|l|}{ MMT } \\
\hline Hip flexor & $4.60 \pm 5.18$ & $3.78 \pm 0.79$ & $3.96 \pm 0.83$ & $3.80 \pm 0.76$ & 0.637 & 0.827 \\
\hline Hip extensor & $4.02 \pm 0.77$ & $3.90 \pm 0.74$ & $4.04 \pm 0.81$ & $3.88 \pm 0.77$ & 0.796 & 0.827 \\
\hline Knee flexor & $4.00 \pm 0.83$ & $3.80 \pm 0.90$ & $4.00 \pm 0.83$ & $3.78 \pm 0.89$ & 1.00 & 0.827 \\
\hline Knee extensor & $4.00 \pm 0.83$ & $3.80 \pm 0.90$ & $4.00 \pm 0.83$ & $3.84 \pm 0.87$ & 1.00 & 0.637 \\
\hline Ankle dorsiflexor & $3.96 \pm 1.05$ & $3.86 \pm 0.79$ & $4.06 \pm 0.79$ & $3.92 \pm 0.73$ & 0.225 & 0.513 \\
\hline Ankle plantarflexor & $3.98 \pm 1.02$ & $3.92 \pm 0.79$ & $3.94 \pm 0.91$ & $3.92 \pm 0.73$ & 0.593 & 1.00 \\
\hline \multicolumn{7}{|l|}{ ROM } \\
\hline Hip flexion & $99.69 \pm 1.58$ & $99.70 \pm 1.57$ & $99.60 \pm 1.70$ & $99.60 \pm 1.70$ & 0.317 & 0.317 \\
\hline Hip extension & $28.40 \pm 12.35$ & $33.80 \pm 31.83$ & $28.80 \pm 4.35$ & $34.60 \pm 31.41$ & 0.235 & 0.244 \\
\hline Knee flexion & $147.10 \pm 17.09$ & $146.20 \pm 21.56$ & $148.40 \pm 5.75$ & $146.40 \pm 21.26$ & 1.00 & 1.00 \\
\hline Ankle dorsiflexion & $21.30 \pm 18.92$ & $18.47 \pm 4.23$ & $19.70 \pm 3.41$ & $19.18 \pm 5.98$ & 0.234 & 0.419 \\
\hline Ankle plantarflexion & $37.60 \pm 7.37$ & $36.63 \pm 10.17$ & $38.30 \pm 7.11$ & $38.27 \pm 7.18$ & 0.31 & 0.08 \\
\hline \multicolumn{7}{|l|}{ Posturography } \\
\hline WDI & \multicolumn{2}{|c|}{$10.35 \pm 6.06$} & \multicolumn{2}{|c|}{$11.48 \pm 8.24$} & \multicolumn{2}{|c|}{0.24} \\
\hline Stability index & \multicolumn{2}{|c|}{$33.35 \pm 23.93$} & \multicolumn{2}{|c|}{$31.71 \pm 18.99$} & \multicolumn{2}{|c|}{0.63} \\
\hline MBI & \multicolumn{2}{|c|}{$90.70 \pm 9.77$} & \multicolumn{2}{|c|}{$92.76 \pm 8.54$} & \multicolumn{2}{|c|}{$0.012^{*}$} \\
\hline MBI-gait & \multicolumn{2}{|c|}{$20.62 \pm 4.60$} & \multicolumn{2}{|c|}{$21.56 \pm 4.00$} & \multicolumn{2}{|c|}{$0.036^{*}$} \\
\hline BBS & \multicolumn{2}{|c|}{$41.68 \pm 10.27$} & \multicolumn{2}{|c|}{$44.72 \pm 9.88$} & \multicolumn{2}{|c|}{$0.000^{*}$} \\
\hline TUG & \multicolumn{2}{|c|}{$21.25 \pm 16.14$} & \multicolumn{2}{|c|}{$16.82 \pm 11.50$} & \multicolumn{2}{|c|}{$0.000^{*}$} \\
\hline KFES-I & \multicolumn{2}{|c|}{$36.34 \pm 12.46$} & \multicolumn{2}{|c|}{$30.64 \pm 11.89$} & & \\
\hline
\end{tabular}

Values are presented as mean \pm standard deviation.

IDS, initial double stance; TDS, terminal double stance; MMT, manual muscle test; ROM, range of motion; WDI, Weight Distribution Index; MBI, Modified Barthel Index; BBS, Berg Balance Scale; TUG test, Timed Up and Go test; KFES-I, Korean version of Fall Efficacy International Scale.

${ }^{\text {a) }}$ Knee extensor $(\mathrm{left}=0.637$, right $=1.000)$.

${ }^{*} \mathrm{p}<0.05$.

relationship between FOF and fall risk [21,22]. This was also applied in elderly individuals with stroke. It was proved to be an effective measurement tool to assess FOF in stroke patients [23]. In addition, one study has shown that the number of falls is positively correlated with FES $(\mathrm{r}=0.215, \mathrm{p}=0.019)$ in idiopathic Parkinson disease [24].

FES-I was translated into Korean with excellent validity and reliability in 2010 [14]. However, studies about effects 
of exercise on falling in elderly people in Korea were limited. Lim et al. [22] have evaluated short-term and longterm effects of integrated fall prevention program comprised of exercises and found that such program could reduce the rate of falls in recent 1 year after 1 year of follow-up. However, such program had no significant effect on FOF with FES or $\mathrm{ABC}$ ( $\mathrm{p}=0.53$ or $\mathrm{p}=0.35$, respectively), but not using KFES-I [22]. On the contrary, Jung et al. [25] have evaluated the relationship between exercise effect and FOF using KFES-I. KFES-I was significantly improved in the multifactorial program group $(\mathrm{p}<0.05)$. However, the number of enrolled participants was small $(n=25$ in two groups) and all patients were stroke-patients in recent 1 year. On the basis of these limitations, we applied an exercise program composed of stretching, strengthening, and balancing exercises for 8 weeks in a group-based manner. Then we compared FOF using KFES-I and other quantitative gait and balance variables through the exercise program in community-dwelling elderly men. As a result, there were significant improvements in KFES-I, stride length, knee extensor maximal strength at an angular velocity of $120 \mathrm{rad} / \mathrm{s}$ and $210 \mathrm{rad} / \mathrm{s}$, MBI, BBS, and TUG scores after exercises (Table 2). In addition, KFESI showed significantly negative correlation with MBI $(\mathrm{r}=-0.35, \mathrm{p}=0.013)$ and MBI gait parameters $(\mathrm{r}=-0.341$, $\mathrm{p}=0.015)$, meaning that reducing FOF might continue to improve gait ability. Unfortunately, there was no significant correlation between KFES-I and other quantitative gait or balance parameters. Furthermore, the comparison based on fall experience revealed that KFES-I and MBI-gait were improved in both groups. However, they showed no significant difference between the two groups ( $\mathrm{p}=0.244$ and $\mathrm{p}=0.374$, respectively).

Most studies have emphasized the importance of reducing FOF to prevent falls. Results of the present study revealed that an 8-week exercise program decreased FOF and its correlation with other gait parameters. Through such exercise, FOF decrement and improved gait parameters occurred simultaneously. These results were consistent with other studies showing significant decrease in FOF and improvement for some parameters of gait and balance status [17,18,26-30]. Barnett et al. [26] have studied a 1-year community-based group exercise program of strengthening and balance exercises with significant improvements in postural sway on the floor with eyes open and eyes closed and coordinated stability than controls.
In addition, Cadore et al. [17] have reviewed thirteen trials and concluded that multi-component exercise intervention composed of strength, endurance, and balance training seems to be the best strategy to improve rate of falls, gait ability, balance, and strength performance in physically frail older adults. Donoghue et al. [31] have also reported that the FOF group shows reduced gait speed and stride length with increased double support phase, meaning that FOF can increase fall risk in gait pattern.

Furthermore, there was no significant difference in KFES-I based on fall experience through exercises. However, KFES-I showed significant difference between the two groups before the exercise program (faller $39.18 \pm 12.47$, non-faller $30.82 \pm 10.77 ; \mathrm{p}=0.023$ ) and after the program (faller $33.48 \pm 12.44$, non-faller $25.12 \pm 8.62$; $\mathrm{p}=0.008$ ). This result explains that the elderly might develop FOF after the fall significantly [7]. Effect of the exercise program in fallers showed as good as that in nonfallers based on KFES-I.

Interestingly, although no significant difference was found in MMT of knee extensor muscles (right knee extensor, $\mathrm{p}=1.0$; left knee extensor, $\mathrm{p}=0.637$ ) and flexor muscles (right knee flexor, $\mathrm{p}=1.0$; left knee flexor, $\mathrm{p}=0.83$ ) after exercise, there were significant improvements in both knee maximal strengths at an angular velocity of $120 \mathrm{rad} / \mathrm{s}$ and $210 \mathrm{rad} / \mathrm{s}$ by isokinetic dynamometer (all $\mathrm{p}<0.000$ ) (Table 2). This result showed strengths of quantitative measurements on evaluation. Even though not all improvements were significant, it was a strength of this study that more quantitative gait and balance variables were evaluated using gait analysis, posturography, and isokinetic dynamometer parameters.

This study has some limitations. First, it does not represent the general population of community-living older individuals. This study only enrolled elderly participants who had completed and were evaluated before and after the exercise program. Thus, results obtained were concentrated on mild gait and balance disturbance. Second, although this study was focused on the relationship between KFES-I and other variables on exercises, a control group was lacking to compare the effect of exercises. Third, women did not participate in our exercise program.

In this study, risk of falls was significantly improved through exercise and that KFES-I had negatively signifi- 
cant correlation with gait ability. In addition, participants showed an increase in gait and balancing ability on quantitative measurements through exercises. Therefore, regular stretching, strengthening, and balancing exercises may help prevent falls in older people.

\section{CONFLICT OF INTEREST}

No potential conflict of interest relevant to this article was reported.

\section{AUTHOR CONTRIBUTION}

Conceptualization: Kang HJ. Methodology: Kang HJ, Jang SW, Chung HS. Formal analysis: Kang HJ, Choi EJ, Jang SW, Jeon KS. Project administration: Kang HJ, Ahn BR, Chung HS. Writing - original draft: Kang HJ, Ahn BR, Choi EJ, Jang SW. Writing - review and editing: Kang HJ, Ahn BR, Chung HS. Approval of final manuscript: all authors.

\section{REFERENCES}

1. Liu Y, Chan JS, Yan JH. Neuropsychological mechanisms of falls in older adults. Front Aging Neurosci 2014;6:64.

2. Ambrose AF, Paul G, Hausdorff JM. Risk factors for falls among older adults: a review of the literature. Maturitas 2013;75:51-61.

3. Casey CM, Parker EM, Winkler G, Liu X, Lambert $\mathrm{GH}$, Eckstrom E. Lessons learned from implementing CDC's STEADI falls prevention algorithm in primary care. Gerontologist 2017;57:787-96.

4. Sohng KY, Moon JS, Song HH, Lee KS, Kim YS. Risk factors for falls among the community-dwelling elderly in Korea. Taehan Kanho Hakhoe Chi 2004;34:148390.

5. Auais M, Alvarado B, Guerra R, Curcio C, Freeman EE, Ylli A, et al. Fear of falling and its association with life-space mobility of older adults: a cross-sectional analysis using data from five international sites. Age Ageing 2017;46:459-65.

6. Zijlstra GA, van Haastregt JC, van Eijk JT, van Rossum E, Stalenhoef PA, Kempen GI. Prevalence and correlates of fear of falling, and associated avoidance of activity in the general population of community-living older people. Age Ageing 2007;36:304-9.

7. Scheffer AC, Schuurmans MJ, van Dijk N, van der Hooft T, de Rooij SE. Fear of falling: measurement strategy, prevalence, risk factors and consequences among older persons. Age Ageing 2008;37:19-24.

8. Friedman SM, Munoz B, West SK, Rubin GS, Fried LP. Falls and fear of falling: which comes first? A longitudinal prediction model suggests strategies for primary and secondary prevention. J Am Geriatr Soc 2002;50:1329-35.

9. Young WR, Mark Williams A. How fear of falling can increase fall-risk in older adults: applying psychological theory to practical observations. Gait Posture 2015; 41:7-12.

10. Tinetti ME, Richman D, Powell L. Falls efficacy as a measure of fear of falling. J Gerontol 1990;45:P239-43.

11. Powell LE, Myers AM. The Activities-specific Balance Confidence (ABC) scale. J Gerontol A Biol Sci Med Sci 1995;50A:M28-34.

12. Yardley L, Beyer N, Hauer K, Kempen G, Piot-Ziegler C, Todd C. Development and initial validation of the Falls Efficacy Scale-International (FES-I). Age Ageing 2005;34:614-9.

13. Dewan N, MacDermid JC. Fall Efficacy Scale-International (FES-I). J Physiother 2014;60:60.

14. Park G, Cho B, Kwon IS, Park BJ, Kim T, Cho KY, et al. Reliability and validity of Korean version of Falls Efficacy Scale-International (KFES-I). J Korean Acad Rehabil Med 2010:34:554-9.

15. Kim KI, Jung HK, Kim CO, Kim SK, Cho HH, Kim DY, et al. Evidence-based guidelines for fall prevention in Korea. Korean J Intern Med 2017;32:199-210.

16. Clemson L, Singh MF, Bundy A, Cumming RG, Weissel E, Munro J, et al. LiFE pilot study: a randomised trial of balance and strength training embedded in daily life activity to reduce falls in older adults. Aust Occup Ther J 2010;57:42-50.

17. Cadore EL, Rodriguez-Manas L, Sinclair A, Izquierdo M. Effects of different exercise interventions on risk of falls, gait ability, and balance in physically frail older adults: a systematic review. Rejuvenation Res 2013;16: 105-14.

18. Park Y, Chang M. Effects of the Otago exercise program on fall efficacy, activities of daily living and quality of life in elderly stroke patients. J Phys Ther Sci 2016;28:190-3. 
19. Schache AG, Baker R, Vaughan CL. Differences in lower limb transverse plane joint moments during gait when expressed in two alternative reference frames. J Biomech 2007;40:9-19.

20. Arfken CL, Lach HW, Birge SJ, Miller JP. The prevalence and correlates of fear of falling in elderly persons living in the community. Am J Public Health 1994;84:565-70.

21. Cumming RG, Salkeld G, Thomas M, Szonyi G. Prospective study of the impact of fear of falling on activities of daily living, SF-36 scores, and nursing home admission. J Gerontol A Biol Sci Med Sci 2000;55:M299305.

22. Lim JY, Lim JY, Park JA, Oh MK, Park WB, Kang EK, et al. Short-term and long-term effects of integrated fall prevention program in the Korean elderly. J Korean Acad Rehabil Med 2010;34:451-7.

23. Azad A, Hassani Mehraban A, Mehrpour M, Mohammadi B. Clinical assessment of fear of falling after stroke: validity, reliability and responsiveness of the Persian version of the Fall Efficacy Scale-International. Med J Islam Repub Iran 2014;28:131.

24. Gazibara T, Tepavcevic DK, Svetel M, Tomic A, Stankovic I, Kostic VS, et al. Recurrent falls in Parkinson's disease after one year of follow-up: a nested case-control study. Arch Gerontol Geriatr 2016;65:1724.

25. Jung Y, Lee K, Shin S, Lee W. Effects of a multifactorial fall prevention program on balance, gait, and fear of falling in post-stroke inpatients. J Phys Ther Sci 2015; 27:1865-8.

26. Barnett A, Smith B, Lord SR, Williams M, Baumand A. Community-based group exercise improves balance and reduces falls in at-risk older people: a randomized controlled trial. Age Ageing 2003;32:407-14.

27. Sherrington C, Whitney JC, Lord SR, Herbert RD, Cumming RG, Close JC. Effective exercise for the prevention of falls: a systematic review and meta-analysis. J Am Geriatr Soc 2008;56:2234-43.

28. Cameron ID, Dyer SM, Panagoda CE, Murray GR, Hill $\mathrm{KD}$, Cumming RG, et al. Interventions for preventing falls in older people in care facilities and hospitals. Cochrane Database Syst Rev 2018;9:CD005465.

29. Freiberger E, Haberle L, Spirduso WW, Zijlstra GA. Long-term effects of three multicomponent exercise interventions on physical performance and fall-related psychological outcomes in community-dwelling older adults: a randomized controlled trial. J Am Geriatr Soc 2012;60:437-46.

30. Paul SS, Thackeray A, Duncan RP, Cavanaugh JT, Ellis TD, Earhart GM, et al. Two-year trajectory of fall risk in people with Parkinson disease: a latent class analysis. Arch Phys Med Rehabil 2016;97:372-379.el.

31. Donoghue OA, Cronin H, Savva GM, O’Regan C, Kenny RA. Effects of fear of falling and activity restriction on normal and dual task walking in community dwelling older adults. Gait Posture 2013;38:120-4. 